\title{
Um eterno Burgo podre? A política na capital federal na Primeira República
}

\author{
Surama Conde Sá Pinto*
}

\begin{abstract}
Resumo
Este artigo tem como objetivo discutir alguns enunciados presentes nos meios político, jornalístico e acadêmico relativos ao funcionamento da política carioca na Primeira República. Em particular, são revisitadas e discutidas ideias sobre a origem dos membros das elites políticas e das instituições partidárias da cidade, o papel do Senado e dos prefeitos na política local e a atuação da bancada carioca no Congresso.
\end{abstract}

Palavras-chave: Dinâmica política; cidade do Rio de Janeiro; Primeira República.

\begin{abstract}
This article aims to discuss some statements present in the political, journalistic and academic sphere about carioca policy in the Brazilian First Republic. In particular, we revisit and discuss ideas about the origin of the members of the political elites and party institutions in the city, the role of the Senate and of the mayors in local politics and the performance of Rio de Janeiro parliamentarians in Congress.
\end{abstract}

Keywords: Political dynamics; Rio de Janeiro city; First Republic.

\section{Introdução}

Nos discursos proferidos por parlamentares que fizeram parte da representação carioca na Primeira República, a expressão burgo podre era utilizada com frequência para caracterizar a política da cidade do Rio de Janeiro. Soava quase como um desabafo. Essa imagem depreciativa estava associada à percepção do que seria uma intensa ação do governo federal no campo político carioca. Cabe aqui a pergunta: O que tal imagem guarda de verdade? A atuação do governo federal, de fato, cerceou o jogo político local, conferindo limites bastante precisos à sua existência no período? Qual o papel, na prática, das instituições políticas locais e qual o sentido conferido à ideia de autonomia carioca pelos membros das elites políticas cariocas?

\footnotetext{
* Doutora em História Social pelo PPGHIS/UFRJ, professora-adjunta do Instituto Multidisciplinar (IM) da UFRRJ. suramaconde@uol.com.br
} 
Ao examinarmos a produção acadêmica, é possível perceber que, até fins da década de 1980, período em que se observa um sensível crescimento na produção de estudos sobre a cidade do Rio de Janeiro, a história política carioca não era objeto de maior interesse por parte dos pesquisadores (Lobo, 1995; Falcon, 1995). Dois fatores parecem estar diretamente relacionados a essa tendência. Um deles é o processo de descrédito experimentado pela história política, produto de uma série de críticas formuladas por historiadores identificados com paradigmas dominantes na historiografia até os anos 1980 do século XX. Esse movimento, embora não tenha impedido que na produção acadêmica dos Centros de Pós-graduação sediados no país o político fosse mantido como principal referência em seu discurso (D’Aléssio e Janotti, 1996), fez com que novos objetos e abordagens, sobretudo aquelas que privilegiavam o econômico e o social, bem como o resgate das massas, ganhassem maior espaço, transferindo muitas vezes para a Sociologia e/ou para a Ciência Política o estudo de temáticas como elites e Estado (Burke, 1992; Himmelfarb, 1987; Remond, 1996:14). O outro é a ampla difusão nos meios acadêmico, jornalístico e político da ideia da nacionalização da política carioca. De acordo com essa ideia, por sediar a capital do país e não gozar efetivamente de autonomia administrativa, os políticos cariocas teriam sido absorvidos pelo debate político nacional e, consequentemente, a cidade teria encontrado sérias dificuldades em organizar-se enquanto sujeito político. Como desdobramento direto dessa situação, a história política carioca confundir-se-ia com a história política nacional.

Éno bojo dessa tendência que pode ser inserida a produção de um grupo de pesquisadores que, em seus trabalhos, abordando temáticas variadas, sublinharam a forte interferência do governo federal na dinâmica política carioca ao longo da Primeira República (Bastos, 1984; Carvalho, 1987; Silva, 1988; Veneu, 1987; Weid, 1984).

Em meio a esses estudos, em função da repercussão e influência que continua exercendo sobre diversos autores, merece destaque o de José Murilo de Carvalho. Em Os Bestializados, Carvalho, apesar de estar voltado para a análise do processo de construção da cidadania republicana, afirma que a cidade do Rio de Janeiro na virada do século XX reuniria duas características fundamentais para entender sua dinâmica política. Por um lado, ela guardava importantes semelhanças com o modelo proposto por Max Weber de cidade antiga, pré-burguesa. Por outro, a posição de sede do governo federal e centro administrativo gerava nela uma forte predominância do Estado, constituindo o governo municipal o melhor reflexo desta tendência. Sendo os prefeitos nomeados pelo Executivo Federal, o papel que desempenhavam não excederia muito o de interventores do governo. Repetia-se, assim, na capital federal, segundo Carvalho, a tradicional fórmula utilizada durante o Império com relação aos presidentes de províncias que, nomeados pelo governo central, eram figuras, na maior parte dos casos, alheias à vida política local, cabendo-lhes fundamentalmente o desempenho de funções administrativas. Da mesma forma, o Conselho Municipal do Distrito Federal (órgão Legislativo local) não reuniria condições de estabelecer limites à atuação do prefeito, já que não gozava da prerrogativa de veto às medidas por ele propostas, atribuição delegada ao Senado.

O somatório dessas peculiaridades, aliado ao fenômeno da fraude eleitoral e à desvalorização do voto, resultaria na descaracterização da representação municipal e na constituição de "repúblicas populares", distantes da política oficial, analisadas em seu trabalho sob o prisma da cidadania informal.

Mas se nos anos 1980 a política carioca não foi focalizada com prioridade na produção acadêmica, na década de 1990 assistiu-se a uma sensível modificação neste quadro. 
Nos centros de Pós-graduação do Estado do Rio de Janeiro começaram a ser produzidas teses e dissertações afinadas com a proposta de resgatar a trajetória política da cidade do Rio (Almeida, 1996; Freire, 2000; Motta, 1997; Sarmento, 1996). Esse maior interesse não foi fortuito. Está relacionado a uma convergência de fatores de ordem interna e externa à própria pesquisa histórica. No que diz respeito aos fatores externos, particularmente, o aniversário de 25 anos da fusão do antigo Estado da Guanabara com o Estado do Rio e os debates surgidos na ocasião estimularam pesquisadores a repensar a experiência política da cidade do Rio de Janeiro.

De uma maneira geral, essa produção, apesar de privilegiar em termos de corte cronológico diferentes períodos do regime republicano, apresenta um conjunto de características comuns. O uso da abordagem da cultura política e a forte influência no plano teórico da obra de Pierre Bourdieu são algumas delas. ${ }^{1}$ A principal, contudo, é o empenho em relativizar a ideia da nacionalização da política carioca.

Em relação a esse aspecto, sem deixar de reconhecer que a nacionalização foi um fenômeno marcante na vida política da cidade e que ao longo do tempo em que o Rio sediou a capital do país o governo federal sempre atuou no sentido de neutralizar as reivindicações políticas locais, o que esses novos estudos descortinaram foi o outro lado da moeda, ou seja, as estratégias acionadas pelas elites políticas cariocas em diferentes conjunturas para atuarem nesse campo político partilhado de forma desigual.

Em meio a esses trabalhos merece destaque o livro Uma capital para a República: poder federal e forças locais no campo político carioca (Freire, 2000), único em termos de corte cronológico localizado na Primeira República. Nele a preocupação central do autor é examinar o processo de construção política da capital republicana no período considerado definidor de seus traços fundamentais, ou seja, entre 1889 e 1906.

Utilizando como base documental os anais da Câmara e do Senado e a imprensa, Américo Freire, autor do referido estudo, defende que o modelo político de capital vitorioso, gestado num longo processo, consistiu em um conjunto institucional de difícil manejo com a presença de órgãos de diferentes níveis (federal e municipal) e sem um claro centro de gravidade.

Apesar da grande contribuição que o trabalho de Freire e os estudos anteriormente realizados representam nos debates sobre a dinâmica política carioca na Primeira República, várias questões relativas à ação dos representantes cariocas no Congresso, ao funcionamento da política local e ao papel nela desempenhado por diferentes instituições durante muito tempo permaneceram sem ser tratadas.

Nosso objetivo neste artigo é contribuir para esse debate, trazendo à discussão alguns enunciados presentes nas análises indicadas anteriormente que, na falta de pesquisas empiricamente fundamentadas, acabaram se tornando lugar comum, sobretudo nos meios político, jornalístico e acadêmico. Faço referência, em particular, às ideias: da origem heterogênea dos membros das elites políticas cariocas, da suposta debilidade das instituições partidárias da cidade, de que o Senado era o órgão supervisor ou árbitro na política carioca, da falta de coesão da bancada carioca no Congresso, pelo fato de essas elites terem sido, em grande medida, absorvidas pelo debate político nacional, e a de que o prefeito era um mero administrador de contas ou interventor do governo federal no campo político da cidade.

1 Esta influência se manifesta no uso de conceitos formulados pelo sociólogo francês como poder simbólico, capital político, campo político, estratégia, entre outros. Ver do autor: BOURDIEU, Pierre. O Poder Simbólico. Rio de Janeiro: Bertrand Brasil, 1989. 
O recorte aqui adotado compreende o período que vai de 1909 a 1922. A conjuntura engloba a Campanha Civilista (movimento que lançou a candidatura de Rui Barbosa para o Executivo federal no pleito de 1910) e a Reação Republicana (movimento que lançou a candidatura dissidente do chefe fluminense Nilo Peçanha e do político baiano J. J. Seabra à presidência e à vice-presidência da República no pleito de 1922). A opção não é fortuita. Nessas duas campanhas presidenciais que balizam este artigo, a questão da autonomia política da cidade do Rio foi tema de discussão. Cabe também destacar que a política carioca tem sido estudada em conjunturas de redefinição da política nacional e não em contextos menos conturbados, embora também marcados por certa instabilidade, daí a importância de análises em fases em que o modus faciendi da República já havia sido definido.

Antes de responder às questões levantadas no início deste artigo, é importante definir o que aqui se entende por elites políticas cariocas, bem como esboçar a configuração políticoadministrativa do município.

Para efeitos deste artigo, o termo elites políticas será utilizado de forma instrumental para englobar prefeitos, deputados federais e senadores que, independentemente de terem ou não nascidos na cidade do Rio de Janeiro, fizeram parte da representação política do município, então Distrito Federal, entre 1909 e $1922 .^{2}$

No que diz respeito à configuração político-administrativa do município, é importante destacar que a legislação a respeito da organização e atribuições de Poderes na cidade do Rio sofreu modificações ao longo da Primeira República. Alguns princípios, no entanto, apresentaram longa vigência. Foi o caso daqueles relativos à escolha dos prefeitos. Durante todo o período compreendido entre 1892 e 1930, os chefes do Executivo municipal foram indicados pelo presidente da República, dentre os cidadãos de reconhecida competência.

Antes da promulgação da Lei Orgânica de 1892, os presidentes do Conselho de Intendência Municipal - órgão Legislativo local criado com a implantação do novo regime em substituição à Câmara Municipal - também respondiam pela administração da cidade.

Gozando de uma posiçãoW singular, o Rio de Janeiro era o único município brasileiro com direito à representação no Congresso, composta por 10 deputados e três senadores. Na Câmara, a bancada do Distrito Federal, em termos numéricos, igualava-se à representação do Ceará, ficando atrás de Minas, São Paulo, Bahia, Rio de Janeiro, Pernambuco e Rio Grande do Sul, conforme ilustra a Tabela 1.

Tabela 1

Representação por estado no Congresso Nacional (1891-1930) continua

\begin{tabular}{c|c}
\hline Estados & N. ${ }^{0}$ de Deputados \\
\hline AM & 4 \\
\hline PA & 7 \\
\hline MA & 7 \\
\hline PI & 4 \\
\hline CE & 10 \\
\hline RN & 4 \\
\hline PB & 5 \\
\hline PE & 17 \\
\hline AL & 6 \\
\hline SE & 4 \\
\hline
\end{tabular}

2 As ideias aqui apresentadas foram defendidas no livro Só para iniciados o jogo político na antiga capital federal. Rio de Janeiro: Mauad X, 2011. 
Tabela 1

Representação por estado no Congresso Nacional

(1891-1930) conclusão

\begin{tabular}{c|c}
\hline Estados & N. ${ }^{0}$ de Deputados \\
\hline BA & 22 \\
\hline ES & 4 \\
\hline DF & 10 \\
\hline RJ & 17 \\
\hline MG & 37 \\
\hline SP & 22 \\
\hline GO & 4 \\
\hline MT & 4 \\
\hline PR & 4 \\
\hline SC & 4 \\
\hline RS & 16 \\
\hline TOTAL & 212 \\
\hline
\end{tabular}

Fonte: Abranches (1918)

Eleitos pelos cidadãos ativos da cidade, deputados e senadores tinham seus mandatos estipulados pela Carta de 1891, que estabelecia três anos para os primeiros e oito para os segundos.

Para analisar o perfil desse grupo, composto por quarenta e seis políticos, foi utilizado o método prosopográfico, sendo privilegiado um conjunto de dados, a saber: data/local de nascimento, formação educacional (curso/local), atividade profissional (natureza/local), cargos no Executivo, atividade legislativa e período de gestão na Prefeitura do Rio, no caso dos prefeitos.

Conforme já foi sublinhado, muito se tem especulado sobre a origem desses atores. Aqui, vale a pena reproduzir um trecho da crônica A política no Distrito, de Lima Barreto. Nela, fazendo uso de ironia, Lima Barreto clamava por uma representação do Distrito Federal que fosse própria da cidade, composta por pessoas que não só conhecessem o Rio como também por ele se interessassem. O ponto central da sua crítica incidia basicamente sobre a naturalidade dos representantes da população da capital da República.

Desde que me aposentei, sigo a política do país com um carinho extraordinário; mas, de tôda ela, a que mais me interessa é a do Districto, porquanto sou candidato a intendente municipal, no próximo pleito.

Não é possível que o Rio de Janeiro seja representado diretamente na pessoa de respeitáveis senhores que nasceram no Funchal ou em Alagoas.

O Rio precisa de uma representação própria, de pessoas que o conheçam e por êle se interessem.

Na Câmara, é uma lástima. Nenhum dos deputados pelo Rio de Janeiro, com poucas exceções, o conhece. O Senhor Paulo de Frontin, cujo clericalismo tanto me afasta dêle, é uma das exceções, não só por sua competência e ilustração, como por ser um carioca da gema.

No Senado, é outra desgraça, tanto assim que tem para senador Octacílio Camará, moço de vários títulos de doutor, mas muito bom para ocupar a cátedra do Senhor Victorino Monteiro.

O Conselho Municipal é tudo o que o Rio de Janeiro tem de falso.

Muito poucos nasceram no Rio e quase todos só conhecem o centro da cidade e o bairro em que vivem.

É preciso reagir contra êsse estado de coisas. Urge que tomemos, nós cariocas legítimos ou honorários, uma providência ... (Barreto, 1956)

De fato, o cronista carioca não estava de todo equivocado quando apontava para a maciça presença de pessoas oriundas dos mais variados cantos do país. Com 65,2\% de seus 
membros não naturais na cidade, pode-se afirmar que a heterogeneidade era um dos principais traços das elites políticas cariocas entre 1909-1922. Esse era um verdadeiro diferencial do grupo, em comparação com as elites políticas de algumas unidades da Federação no período.

Conforme destacou John Wirth, Minas Gerais era conhecida por sua homogeneidade e reserva em relação a estranhos, possuindo apenas 13\% de sua elite nascida fora do estado (Wirth, 1975:204). Já a elite pernambucana, estudada por Levine, continha 15\% de outsiders (Levine, 1975). São Paulo é um caso à parte. Apesar de apresentar um percentual maior de elementos não naturais do estado (19\%), o fenômeno da provincialização, ou seja, a ênfase progressiva no recrutamento de membros dentro do próprio estado também foi observada por Love. Isto se verificou apesar de, em São Paulo, a imigração e a migração nacional terem experimentado grande êxito, permitindo a incorporação, ainda que lenta, de descendentes de imigrantes no seio da elite governante (Love, 1975:224). No que diz respeito a este aspecto, a similaridade entre a cidade do Rio e São Paulo é grande (Pinto, 2011:41).

A exemplo de São Paulo, a cidade do Rio foi um dos principais centros acolhedores de imigrantes e migrantes durante a Primeira República. Atraídos por oportunidades profissionais, esse contingente transformou a paisagem carioca, conferindo à população da cidade um traço bastante peculiar. Levando-se em conta essa realidade, parece bastante razoável afirmar que nada mais apropriado para a cidade ter uma representação sensível a essa peculiaridade e que a tenha incorporado à sua constituição. Assim, ao ser composta por um número alto de pessoas não nascidas na cidade, as elites políticas cariocas, de certo modo, estavam em sintonia com as características da própria população do Distrito Federal.

Por outro lado, embora esse grupo tenha sido em grande medida constituído por outsiders, seria equivocado concluir que não apresentava elementos em comum. A geração à qual pertencia a maioria desses atores, a formação superior em cursos tradicionais e nos mesmos estabelecimentos de ensino, os semelhantes padrões de carreiras e o local de exercício profissional conferiram ao grupo certa homogeneidade, aproximando-o, inclusive, do perfil das elites regionais do país no mesmo período.

Quase a metade dos membros das elites políticas cariocas $(47,83 \%)$ pertencia à primeira geração de políticos da República, ou seja, nascera antes de 1869, tendo-se ocupado de problemas políticos e econômicos, como a abolição, a instituição do novo regime, a inflação causada pelo Encilhamento e a dívida externa do país.

No que diz respeito à educação, pelo menos $80 \%$ dos políticos analisados tinham curso superior, havendo se formado nas Escolas de Ensino Superior, sediadas no país, em cursos tradicionais como o de Direito (34,78\%), Medicina (23,91\%) e, em menor número, o de Engenharia Civil e Militar (8,70\% e 13,04\%, respectivamente). Na República, a formação superior continuou funcionando como um verdadeiro divisor de águas, pois, embora em 1920 a cidade possuísse os índices mais altos de alfabetização (61,3\%), a maioria da população não tinha semelhante perfil.

Outro elemento importante observado é que, apesar do índice relativo à falta de informação ser alto (41,30\%), aproximadamente 43,48\% dos membros das elites políticas cariocas estudaram na cidade do Rio de Janeiro, que, além de ser o mais importante centro de sociabilidade política, era um dos principais centros de sociabilidade intelectual. O município sediava a princípio três, e posteriormente quatro, importantes escolas formadoras das elites regionais: a Faculdade de Medicina, a Escola Militar, a Escola Central (que receberia a denominação de Politécnica) e, mais tarde, a Faculdade de Ciências Jurídicas e Sociais. Havia ainda o Colégio Pedro II, que conferia o grau de bacharel em Letras aos alunos lá graduados. 
Uma vez concluídos seus estudos, pelo menos 84,78\% do grupo aqui analisado escolheu o Distrito Federal para atuar profissionalmente.

Com base nos dados apresentados até aqui, pode-se afirmar que, apesar de composta 63,04\% por não naturais do município, ao estudarem no Rio de Janeiro e escolherem a cidade para exercer sua atividade profissional, os membros das elites políticas cariocas passavam por um importante processo de socialização que, prolongando-se por espaços como a rua do Ouvidor, os cafés da cidade, teatros, livrarias, clubes elegantes e instituições como o Clube de Engenharia, o Instituto dos Advogados Brasileiros (IAB), o Instituto Histórico e Geográfico Brasileiro (IHGB), a Sociedade Auxiliadora da Indústria Nacional (SAIN) e o Centro Industrial do Brasil (CIB), fazia com que não só desenvolvessem redes de relações e interiorizassem valores em comum, como também que se imiscuíssem nos principais temas e assuntos do município. A própria cidade era um espaço de sociabilidade. Por outro lado, isso não implica afirmar que houve entre esses atores o desenvolvimento de uma forte identidade de grupo nos mesmos moldes daquela observada no comportamento das elites mineira e paulista. Ainda assim, conceber as elites políticas cariocas como um grupo composto por pessoas sem ligações ou enraizamento na cidade é tão equivocado quanto atribuir-lhes como principal característica a debilidade.

\section{O que dizer sobre os partidos políticos da cidade?}

Entre 1909 e 1922 as elites políticas cariocas se organizaram basicamente em torno de três siglas: o Partido Republicano do Distrito Federal (PRDF), criado em fins do século XIX e reorganizado em 1906, a Aliança Republicana (A.R.), organizada em 1917, e o Partido Republicano do Distrito Federal (PRDF), criado em 1918.

Uma análise da experiência dessas agremiações revela que esforços para a construção de uma conciliação interna na política local não faltaram no período. De uma maneira geral, esses experimentos serviram para colocar um pouco de ordem na singular (dada sua especificidade) e ao mesmo tempo multifacetada política da cidade, sobre a qual atuavam diferentes eixos de forças.

As agremiações partidárias cariocas entre 1909 e 1922 não tiveram caráter sazonal, embora os contextos eleitorais as colocassem em maior evidência. O PRDF, partido criado por Barata Ribeiro e reorganizado por Augusto de Vasconcelos em 1906, teve uma sobrevida maior do que o período de uma década, mas a A.R. e o novo PRDF não ficaram atrás: atuaram no campo político carioca num número significativo de pleitos.

A despeito de diferenças em termos de ênfases, as três agremiações também apresentaram programas estruturados de forma consistente, não apenas orientados para questões nacionais, mas propondo soluções para problemas relativos ao cotidiano da cidade, como moradia, higiene, abastecimento e educação.

Esses partidos, por outro lado, enfrentaram sérias dificuldades na domesticação dos conflitos internos e se viram às voltas com constantes rachas e deserções de seus membros.

Os moldes da política mineira de tolerância, transação e amizade nem sempre prevaleceram entre os representantes do Distrito Federal. Os membros das elites políticas cariocas brigavam dentro e fora de casa. Tais conflitos tornavam-se mais evidentes em conjunturas eleitorais, momentos em que novos compromissos eram firmados e, em alguns casos, antigas alianças rompidas. O cerne dos conflitos não tinha como elemento central, contudo, divergências de cunho ideológico. O motor das crises, na maioria dos casos, era 
formado por interesses de ordem pragmática, ou seja, a luta pelo poder de influência na indicação dos candidatos para a composição das chapas. Essa disputa era intensificada em razão da falta de controle sobre a nomeação para cargos e acesso a sinecuras. Ainda assim, não seria correto afirmar que o Rio se afastou do jogo formal das instituições.

A questão da autonomia político-administrativa da cidade até servia de elemento aglutinador entre os grupos políticos cariocas, mas seria um engano pensar que lhe fosse conferido o mesmo significado por todos. O sentido dado a esta ideia variou não só ao longo da história republicana, como de partido para partido. Enquanto, para o Partido Republicano do Distrito Federal (PRDF), o encaminhamento da questão não estava desvinculado da necessidade de mudança da capital, para o prócer dos aliancistas, o engenheiro Paulo de Frontin, era importante que a cidade conquistasse sua autonomia político-administrativa sem o comprometimento do status de capital da República. Isto porque a perda da condição de sede do governo federal era vista como um mal que poderia provocar o esvaziamento econômico da cidade. Um medo não de todo infundado, já que o Rio em meados da década de 1910 havia perdido a condição de principal centro econômico do país para a cidade de São Paulo.

Por outro lado, a despeito das dificuldades assinaladas, os partidos políticos da cidade tiveram o importante papel de estabelecer algum controle sobre os mecanismos de acesso ao governo e, nesse sentido, reduziram o grau de incerteza da política carioca, ao garantir espaço de ação no campo político da cidade para os grupos políticos locais e ordenar, através das chefias nele vinculadas, o voto personalizado do eleitorado da capital. O desempenho eleitoral dessas agremiações é a melhor evidência nesse sentido.

Não foram poucos, contudo, os efeitos mais diretos das dificuldades enfrentadas pelos partidos do Distrito Federal na absorção dos conflitos intraelites. Dentre eles podem ser destacados: a maior vulnerabilidade do campo político carioca à intervenção direta e indireta do Poder Executivo Federal e o comprometimento da possibilidade da cidade do Rio de Janeiro de gozar de um melhor status na política nacional. Mas, ainda assim, a ideia de uma capital neutralizada, sem autonomia política, com instituições débeis, cabendo aos grupos locais apenas uma encarniçada luta pela sobrevivência, não se mostra adequada. O mesmo se pode afirmar em relação ao papel desempenhado pelo Senado no campo político carioca.

\section{Senado: árbitro ou supervisor?}

Em seu livro Uma capital para a República, Américo Freire afirmou que o Senado era um órgão político supervisor das instituições na capital federal (Freire, 2000:10). A interpretação de Freire toma como base a legislação do período. Para se obter uma compreensão mais efetiva do raio de ação dos dois poderes municipais - o Executivo e o Legislativo - bem como o papel do Senado no jogo político carioca na Primeira República, no entanto, tão importante quanto a análise dos dispositivos legais vigentes é o exame de sua aplicação na prática pelas instituições existentes.

A partir desta orientação, e tomando como referencial a análise de todos os vetos dos prefeitos do Distrito Federal a projetos de lei elaborados pelo Conselho Municipal entre 1909-1922 enviados para o Senado, num total de 351 (dos quais 310 tiveram votação final), percebe-se que o Conselho Municipal, através de seus representantes, reagiu às iniciativas intervencionistas federais, traduzidas numa legislação que restringia o raio de ação do Legislativo local, elaborando projetos de leis nos quais esses dispositivos jurídicos eram ignorados. 
Tabela 2.

Natureza das matérias vetadas pelos Prefeitos (1909-1922)

\begin{tabular}{|c|c|c|c|c|c|c|c|c|c|c|c|c|}
\hline Natureza dos Vetos & $\begin{array}{c}1909 \\
\text { N. }{ }^{\circ}\end{array}$ & $\begin{array}{c}1910 \\
\text { N. }{ }^{\circ}\end{array}$ & $\begin{array}{c}1911 \\
\text { N. }{ }^{0}\end{array}$ & $\begin{array}{c}1912 \\
\text { N. }{ }^{0}\end{array}$ & $\begin{array}{c}1913 \\
\text { N. }{ }^{\circ}\end{array}$ & $\begin{array}{c}1914 \\
\text { N. }{ }^{0}\end{array}$ & $\begin{array}{c}1915 \\
\text { N. }{ }^{0}\end{array}$ & $\begin{array}{c}1916 \\
\text { N. }{ }^{\circ}\end{array}$ & $\begin{array}{c}1917 \\
\text { N. }{ }^{0}\end{array}$ & $\begin{array}{c}1921 \\
\text { N. }{ }^{0}\end{array}$ & $\begin{array}{c}1922 \\
\text { N. }\end{array}$ & Total \\
\hline $\begin{array}{l}\text { Medidas que Beneficiavam } 0 \\
\text { Funcionalismo }\end{array}$ & 17 & 2 & 28 & 11 & 6 & 19 & 2 & 4 & 8 & 56 & 91 & 244 \\
\hline Valor Locativo de Prédios & - & - & - & - & - & - & 1 & - & - & - & - & 1 \\
\hline Ensino Municipal & 1 & & 5 & & & & & & 2 & 2 & 6 & 16 \\
\hline Limita Atribuições do Prefeito & & & & & & & & & & 1 & & 1 \\
\hline Impostos & 1 & & 2 & & & & & & & 2 & 2 & 7 \\
\hline Posturas Municipais & 1 & & 9 & 1 & & & & 1 & & 6 & 1 & 19 \\
\hline Contratações e Concessões & 2 & & 4 & 1 & 4 & 2 & & 1 & & 6 & 1 & 20 \\
\hline Projeto de Orçamento & & 1 & & & & & & & & & & 1 \\
\hline Alteração na Legislação & & 3 & & & 1 & & & & & & 1 & 5 \\
\hline $\begin{array}{l}\text { Autorização p/ Prefeito Reorg. } \\
\text { Patrimônio }\end{array}$ & & & & & & & & 1 & & & & 1 \\
\hline $\begin{array}{l}\text { Obras/ } \\
\text { Construções }\end{array}$ & & & 2 & 2 & & & & & & & & 4 \\
\hline Criação de Hospitais & & & 1 & & & & & & 1 & & & 2 \\
\hline Regras/Matança de Gado (Mat & & & & & & 1 & & & & & & 1 \\
\hline Abertura de Concorrência & & & 1 & & & & & & & & & 1 \\
\hline Outros & & 4 & & & & & & 3 & 1 & 7 & 9 & 24 \\
\hline
\end{tabular}

Sob a rubrica Medidas que Beneficiavam o Funcionalismo Municipal foram agregados projetos de lei que implicavam concessão de aposentadoria, contagem de tempo de serviço, pagamento de vencimentos, gratificacões, diárias, criação de cargos, extensão de vantagens de natureza variada, relativas ao montepio municipal, concessão de licenças com todos os vencimentos, aumento de aposentadorias, reintegração de funcionários, preenchimentos de cargos, abertura de créditos para fins variados, nomeações, extensão a funcionários de benefícios de leis, regras para promoção do funcionalismo, transferência de funcionários, concessão de licença com ordenado, jubilação, efetivação de funcionários, estipulação e aumento de vencimentos, regras de jubilação e aposentadoria, equiparação de vencimentos e organização de quadro de funcionários.

Nem 1/3 das resoluções do Conselho, que foram objeto de veto, estava de acordo com as atribuições do Legislativo municipal estipuladas pela legislação do período. Não competia ao Conselho nomear, aposentar, conceder licenças fora das regras vigentes, reintegrar funcionários, aumentar ou equiparar vencimentos de funcionários municipais, como os intendentes fizeram durante todo o período. Tais iniciativas eram privativas do Prefeito. $\mathrm{O}$ Poder Legislativo local parece ter mantido certa nostalgia de uma fase em que acumulava também funções administrativas e tinha um raio de ação maior do que o Executivo municipal. Não se limitar ao código legal foi um meio utilizado pelos intendentes para tentar reconquistar o campo de atuação subtraído pela legislação reguladora das atribuições dos poderes locais.

Com base na utilização desta estratégia, os legisladores municipais não só mostraram resistência ao esvaziamento de suas prerrogativas, como conseguiram fazer com que o Senado, entre 1909-1922, reconhecesse como legítimo o direito do Conselho, em determinadas conjunturas, de produzir leis que o código vigente impedia.

Outro elemento evidenciado é que, apesar da tensão ter estado presente nas relações entre as duas instâncias de poder local, elas não foram marcadas pelo conflito em tempo integral. 
Tabela 3

Pareceres elaborados no Senado sobre vetos dos Prefeitos

do Distrito Federal (1909-1922)

\begin{tabular}{|c|c|c|}
\hline \multicolumn{3}{|c|}{ Pareceres } \\
\hline Ano & N. ${ }^{0}$ & $\%$ \\
\hline 1909 & 22 & 6,27 \\
\hline 1910 & 3 & 0,85 \\
\hline 1911 & 59 & 16,81 \\
\hline 1912 & 15 & 4,27 \\
\hline 1913 & 10 & 2,85 \\
\hline 1914 & 22 & 6,27 \\
\hline 1915 & 7 & 1,99 \\
\hline 1916 & 11 & 3,13 \\
\hline 1917 & 13 & 3,70 \\
\hline 1921 & 78 & 22,22 \\
\hline 1922 & 111 & 31,62 \\
\hline total & 351 & 100,00 \\
\hline
\end{tabular}

Conforme ilustra a Tabela 3, o número de vetos enviados ao Senado para avaliação de litígios envolvendo os poderes locais variou bastante ao longo do período. Houve anos em que a Câmara Alta teve pouco trabalho, conforme ocorrido em 1910. Em outros períodos, contudo, esse número chegou a 111, como se observa em 1922, durante a gestão de Carlos Sampaio. A ideia da existência de um permanente conflito entre o Executivo e Legislativo municipal precisa, assim, ser reavaliada. Não se trata aqui de negar a existência de tensão entre os dois Poderes. Querelas e pendengas estiveram presentes ao longo do período, mas houve fases em que a convivência entre prefeitos e intendentes foi um pouco mais harmoniosa e outras em que a tensão foi acirrada em função da falta de sucesso nos canais de negociação.

Outra ideia que precisa ser revista é a de que o Senado atuava em parceria preferencial com os prefeitos, ou seja, agia no período em total consonância com os chefes do Executivo local referendando suas resoluções. Empiricamente esse enunciado não se sustenta.

Tabela 4.

Pareceres favoráveis e pareceres contrários aos vetos dos Prefeitos do Distrito Federal (1909-1922)

\begin{tabular}{c|cc|cc}
\hline \multirow{2}{*}{ Ano } & \multicolumn{2}{|c|}{$\begin{array}{c}\text { Pareceres Favoráveis aos Vetos } \\
\text { N. }\end{array}$} & \% & \multicolumn{2}{c}{$\begin{array}{c}\text { Pareceres Contrários aos Vetos } \\
\text { N. }\end{array}$} \\
\hline 1909 & 14 & 3,99 & 8 & 2,28 \\
\hline 1910 & 1 & 0,28 & 2 & 0,57 \\
\hline 1911 & 52 & 14,81 & 7 & 1,99 \\
\hline 1912 & 9 & 2,56 & 6 & 1,71 \\
\hline 1913 & 10 & 2,85 & 0 & 0,00 \\
\hline 1914 & 9 & 2,56 & 13 & 3,70 \\
\hline 1915 & 2 & 0,57 & 5 & 1,42 \\
\hline 1916 & 7 & 1,99 & 4 & 1,14 \\
\hline 1917 & 5 & 1,42 & 8 & 2,28 \\
\hline 1921 & 54 & 15,38 & 24 & 6,84 \\
\hline 1922 & 43 & 12,25 & 68 & 19,37 \\
\hline Total: & $\mathbf{2 0 6}$ & $\mathbf{5 8 , 6 9}$ & $\mathbf{1 4 5}$ & $\mathbf{4 1 , 3 1}$ \\
\hline & & &
\end{tabular}


O exame do cotidiano do jogo político carioca revelou que a Câmara Alta desempenhou um papel maior do que o de simples órgão político supervisor das instituições da capital ou de árbitro. No exercício da prerrogativa de apreciação dos vetos dos prefeitos, que lhe foi conferida pela legislação federal visando esvaziar o jogo político carioca, o Senado acabou atuando em alguns momentos como uma espécie de fiador do raio de ação do Conselho Municipal. Isso se deu basicamente através do desrespeito aos dispositivos legais e da garantia dada à sanção de uma série de projetos de lei elaborados pelo Conselho Municipal que foram vetados pelos prefeitos do Distrito Federal sob a alegação da invasão de atribuição e da falta de competência do Legislativo municipal para legislar sobre a matéria (Pinto, 2011:136).

Tabela 5.

Pareceres votados no Senado de vetos dos Prefeitos do Distrito Federal $(1909-1922)$

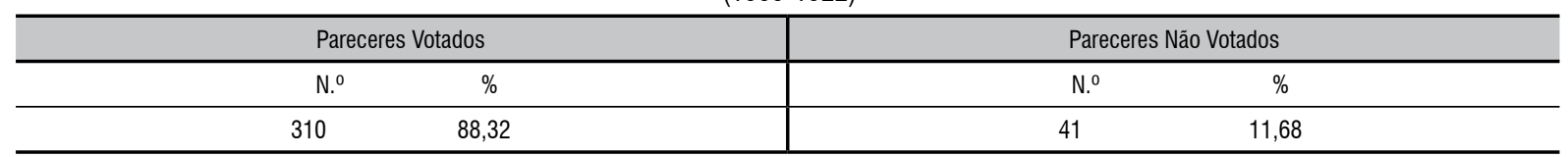

Tabela 6.

Resultado da Votação Final

\begin{tabular}{cc|cc}
\hline \multicolumn{2}{c|}{ Vetos Mantidos em Votação } & \multicolumn{2}{c}{ Vetos Rejeitados em Votação } \\
\hline N. ${ }^{0}$ & $\%$ & N. ${ }^{0}$ & $\%$ \\
\hline 188 & 60,64 & 122 & 39,36 \\
\hline
\end{tabular}

Esta tendência esteve presente durante todo o período, embora com maior intensidade em conjunturas marcadas pela deterioração das condições de vida da população carioca, pelo agravamento das dificuldades enfrentadas pelo funcionalismo público municipal, pelo tipo de relação estabelecido entre prefeitos e demais poderes e instâncias de poderes e, também, pela ação dos senadores cariocas em defesa do Legislativo local. Se o Senado foi menos árbitro e mais fiador, o que dizer sobre a performance dos deputados cariocas no Parlamento?

\section{A bancada carioca no Congresso: Um saco de gatos?}

\footnotetext{
A política do Distrito sempre foi desunida. Enquanto todas as bancadas, na Câmara, tinham os seus 'leaders,' na carioca não havia nada disso: cada um era 'leader' de si mesmo [...]

Por semelhante feição da actividade dos políticos do Districto, sempre há de existir quem duvide da possibilidade de accomodação nesse velho saco de gatos.
}

(Diário da Noite, edição de 11 de dezembro de 1931)

Nem total subordinação ao governo nem independência irrestrita. Assim pode ser definida a atuação da bancada carioca no Congresso. A análise da ação deste grupo na Câmara dos Deputados, através do mapeamento de todos os seus pronunciamentos, revela que as ideias de uma completa submissão à maioria ou de uma constante oposição à base governista não se sustentam. O comportamento dos representantes da cidade no Legislativo federal oscilou ao longo do período em função de conjunturas e questões colocadas na agenda política do momento.

Faltou coesão interna em torno de questões como as diretrizes da política econômicofinanceira adotada pelogoverno brasileiro entre 1909 e 1922, a ação de Pinheiro Machado na política nacional e carioca e as disputas abertas pelas campanhas presidenciais de 1909 e 1922 (Pinto, 
2011:162). Nem por isso, contudo, as elites políticas cariocas deixaram de mostrar capacidade de atuação em conjunto. Algumas questões e determinadas conjunturas foram capazes de mobilizar deputados e senadores da representação carioca, fazendo com que, ainda que temporariamente, colocassem de lado suas diferenças. Foram os casos das questões relativas a recursos financeiros, higiene, educação e habitação para o Distrito Federal e dos contextos marcados pela alta dos gêneros alimentícios em 1917, a onda de greves que eclodiu no mesmo ano e a epidemia de febre espanhola, em 1918, que assolou a cidade fazendo um grande número de vítimas.

No federalismo frouxo e desigual que caracterizava o sistema político brasileiro no período, a barganha no Congresso era uma importante forma dos estados ajustarem seus interesses conflitantes e as elites políticas cariocas perceberam as regras do jogo. Em vez de socar estátua (expressão utilizada na época para designar lutar sem resultado) os representantes da cidade desenvolveram suas estratégias. A principal delas foi o que denominamos pragmatismo oportunista e deve ser entendida como a aproximação com o governo e o firmamento de alianças e compromissos com os representantes do Executivo federal e local. Em duas conjunturas este movimento se mostrou com nitidez quase cristalina: no quadriênio de Hermes da Fonseca e consequentemente na gestão de Bento Carneiro como prefeito do Distrito Federal e, com menor proporção, na presidência de Wenceslau Brás e na administração de Amaro Cavalcanti na prefeitura carioca (Pinto, 2011:182). O êxito desta manobra política em parte deveu-se aos esforços de unificação dos grupamentos políticos da cidade realizados por Augusto de Vasconcelos e por Paulo de Frontin, através do PRDF transformado em PRC do Distrito Federal nos anos 1910 e da Aliança Republicana, criada em 1917. Nessas conjunturas, compor com o governo foi a estratégia utilizada por estes grupos para garantir algum espaço de atuação no campo político carioca.

Isso não significa que não tenha havido dissidências ou vozes oposicionistas, até porque foi evidenciada a dificuldade da bancada carioca de atuar em conjunto no Congresso, de forma coesa. Ainda assim, este padrão de comportamento nos permite afirmar que as elites políticas cariocas não atuaram no período nem como meros fantoches do Executivo federal, nem como adversárias entrincheiradas. Em vários momentos esses atores mostraram capacidade de ação própria, procedendo independentemente ao comando ou tutela de uma maioria governista. Atuando desta forma, os representantes da bancada carioca, apesar de uma série de constrangimentos de ordem legal, exerceram certo grau de autonomia.

\section{E o prefeito?}

Ao longo da Primeira República, o governo federal procurou assegurar uma alta rotatividade ao cargo de prefeito do Distrito Federal. A dança de cadeiras no casarão do Campo de Santana, sede da Prefeitura, entretanto, adquiriu um ritmo mais lento no período compreendido entre 1909 e 1922, quando à frente do Executivo da municipalidade estiveram dez prefeitos. ${ }^{3}$

A duração das gestões variou de forma significativa, sendo algumas relativamente longas, com mais de quarenta meses, e outras extremamente curtas. A produção que analisa essas administrações, tradicionalmente as aborda em seu conjunto, priorizando as

3 Entre 1909 e 1922 foram prefeitos do Distrito Federal: Souza Aguiar, Serzedelo Corrêa, Bento Manuel Ribeiro Carneiro, Rivadávia Corrêa, Azevedo Sodré, Amaro Cavalcanti, Manuel Cícero Peregrino, Paulo de Frontin, Sá Freire e Carlos Sampaio. 
transformações ensejadas no espaço urbano da cidade a cada novo prefeito (Noronha Santos, 1945; Reis, 1977). Apesar de apresentarem uma boa visão geral do que foram estas gestões, o enfoque utilizado nesses trabalhos tem contribuído para a divulgação da ideia do papel do prefeito como sendo o de um mero administrador ou um simples interventor da União no espaço da cidade.

O enfoque comparativo das gestões de dois prefeitos - Paulo de Frontin e Carlos Sampaio - permite relativizar tanto estas proposições como aquela segundo a qual todas as administrações teriam seguido um mesmo modelo e/ou padrão.

Frontin e Sampaio fazem parte da tríade dos prefeitos engenheiros que escreveram os seus nomes na história da cidade e se tornaram verdadeiros mitos ao lado de Pereira Passos. O primeiro, em função da sua atuação no episódio água em 6 dias, nas obras de construção da Avenida Central e pelo grande número de melhoramentos realizados em sua gestão. O segundo, por sua participação na demolição do Morro do Senado e nos aterros da Praia Formosa, na demolição do cortiço Cabeça de Porco, no arrasamento do Morro do Castelo e nas obras de preparação da cidade para as comemorações do Centenário da Independência.

Pereira Passos, Paulo de Frontin e Carlos Sampaio tinham muitos elementos em comum, mas, principalmente, um Curriculum marcado pela formação educacional realizada na mesma instituição (Escola Politécnica, antiga Escola Central) e pela experiência anterior às suas gestões na Prefeitura carioca em diversos projetos e obras relacionados à evolução urbana da cidade ainda no Império.

Por outro lado, apesar dos dois pertencerem à mesma geração, serem filhos de imigrantes, possuírem a mesma formação educacional e terem trajetórias profissionais bastante similares, chegando inclusive em várias oportunidades a trabalharem juntos, à frente da chefia do Executivo municipal Frontin e Sampaio desenvolveram padrões bastante diferentes em suas gestões.

À frente da prefeitura do Distrito Federal, Frontin imprimiu à sua gestão um padrão agregador e articulador. Esta tendência pode ser evidenciada na análise das medidas por ele adotadas. Uma delas foi a política fiscal praticada. Nos seis meses de sua gestão na prefeitura, Frontin evitou contrariar os interesses ligados ao grande capital da cidade, através da não cobrança do imposto de exportação, criado por Amaro Cavalcanti para aumentar e equilibrar a arrecadação municipal.

Outra iniciativa que lhe rendeu importantes dividendos políticos foi a sistemática sedimentação de alianças com influências políticas de diferentes freguesias, sobretudo do subúrbio e da zona rural, o que lhe permitiu conquistar também o apoio dessas populações através da realização de pequenas obras de melhoramentos. O movimento de aproximação com setores do operariado da prefeitura da capital federal também pode ser tomado como indício importante do padrão observado.

Tal política de alianças e de abertura de canais para as reivindicações de diferentes atores não foi seguida por Carlos Sampaio, que, ao contrário, fechou os tradicionais espaços de atuação dos grupos políticos locais, ao mesmo tempo em que tentou limitar o papel de determinadas instituições no campo político carioca. Sampaio não se preocupou em adular a população da cidade tampouco as chefias locais ou em estabelecer canais de comunicação com os representantes do Distrito Federal no Legislativo local e federal. Pouco inclinado a negociações no que dizia respeito à decisão de assuntos envolvendo a municipalidade, o engenheiro empresário não tinha o perfil de um articulador político como Paulo de Frontin, 
que usou o cargo criado de forma a garantir a ingerência do governo federal no campo político carioca para sedimentar sua base política na cidade (Pinto, 2011:216). A falta de experiência política, o não pertencimento a nenhum partido e a pouca inclinação à chamada política pequena em muito contribuíram para a sua baixa popularidade. Sua forma de atuar chegou inclusive a causar atritos com o Senado por não esperar o pronunciamento daquela Casa em relação a seus inúmeros vetos opostos a medidas do Conselho Municipal, o que lhe valeu o jocoso comentário que ele sofria de "vetomania".

Nas duas gestões também foram diferentes as relações estabelecidas entre os prefeitos e o governo federal. Enquanto Frontin tendeu a imprimir um conteúdo mais autônomo à política carioca, e o melhor indicador a ser apontado aqui é o seu apoio à candidatura dissidente de Rui Barbosa, em 1919, Sampaio inclinou-se para uma maior aproximação em relação às diretrizes do presidente, embora essa aproximação não deva ser interpretada como incondicional, já que enquanto prefeito pleiteou, ainda que sem êxito, a passagem da cobrança de impostos de serviços prestados pelo governo federal para a municipalidade. ${ }^{4}$

Por outro lado, a despeito das diferenças assinaladas, parece não restar maiores dúvidas de que tanto Frontin quanto Sampaio à frente da prefeitura do Distrito Federal ao estabelecer alianças, firmar acordos, lançar mão da cooptação ou mesmo fechar espaços para a atuação de grupos políticos e instituições foram bem mais do que meros administradores ou interventores do governo federal no campo político carioca. O papel que desempenharam foi o de atores políticos.

\section{Considerações finais}

É preciso cautela com enunciados que sublinham determinados traços dos membros das elites políticas cariocas e veiculam ideias relativas à suposta debilidade das instituições partidárias da cidade ao papel do Senado e dos prefeitos na política carioca e à falta de coesão da bancada carioca no Congresso.

Com base no que foi visto aqui, pode-se afirmar que a ação interventiva do governo federal, através de instituições ou da legislação relativa ao município, não inviabilizou a ação dos representantes da cidade, nem sua organização em torno de siglas partidárias, tampouco impediu o desenvolvimento de estratégias de sobrevivência no campo político local partilhado de forma desigual.

Nesse sentido, tanto na sua composição quanto na forma de agir, capitaneando muitas vezes as vozes dissonantes, as elites políticas cariocas acrescentaram a diversidade na arena política nacional da Primeira República.

\section{Referências Bibliográficas}

ABRANCHES, Dunshee de. Governos e Congressos da República (1889-1917). Rio de Janeiro: M. Abranches, 1918. 2 vols.

4 Para uma análise da estrutura tributária e a constituição e organização do fisco brasileiro na Primeira República, ver Oliveira (2010). De acordo com 0 autor, as estruturas tributárias só podem ser compreendidas numa perspectiva histórica, contemplando seus principais determinantes, quais sejam, 0 padrão de acumulação e 0 estágio de desenvolvimento do país, o papel do Estado na vida econômica e social e a correlação de forças sociais e políticas atuantes no sistema. 
ALMEIDA, Mônica Píccolo de. O Rio de Janeiro como hospedaria do Poder Central: Luta autonomista, elite política e identidade carioca (1955-1960). Dissertação de Mestrado. Rio de Janeiro: Universidade Federal do Rio de Janeiro, 1996.

BARRETO, Lima. Política do Distrito. In: BARRETO, Lima. Vida urbana: Artigos e crônicas. São Paulo: Brasiliense, 1956.

BASTOS, Ana Marta Rodrigues. O Conselho de Intendência Municipal: Autonomia e Instabilidade (1889-1892). Rio de Janeiro: CEH/FCRB, 1984.

BOURDIEU, Pierre. O Poder Simbólico. Rio de Janeiro: Bertrand Brasil, 1989.

BURKE, Peter (Org.). A escrita da história: novas perspectivas. São Paulo: Editora da Unesp, 1992.

CARVALHO, José Murilo de. Os Bestializados: O Rio de Janeiro e a República que não foi. São Paulo: Cia das Letras, 1987.

D’ALÉSSIO, Márcia Mansur; JANOTTI, Maria de Lourdes Mônaco. A esfera do político na produção acadêmica dos Programas de Pós-graduação (1985-1994). Revista Estudos Históricos, Rio de Janeiro, vol. 9, n. 17, pp. 123-160, 1996.

FALCON, Francisco J. C. O Rio de Janeiro como objeto historiográfico. Revista Brasileira de História. São Paulo, vol. 15, n. 30, pp. 63-75, 1995.

FREIRE, Américo Oscar Guichard. Uma capital para a República: Poder federal e forças políticas locais no Rio de Janeiro na virada do século XX. Rio de Janeiro: Revan, 2000.

HIMMELFARB, Gertrude. The new history and the old. Massachussets: Massachussets University Press, 1987.

JANOTTI, Maria de Lourdes Mônaco. A República: oposições e consolidação. In: LAPA, José Roberto (org.). História Política da República. São Paulo: Papirus, 1990.

LEVINE, Robert. A velha usina: Pernambuco na federação brasileira (1889-1937). Rio de Janeiro: Paz e Terra, 1975.

LOBO, Eulália Maria L. Historiografia do Rio de Janeiro. Revista Brasileira de História, São Paulo, vol. 15, n. 30, pp. 45-62, 1995.

LOVE, Joseph. A locomotiva. São Paulo na federação brasileira (1889-1937). Rio de Janeiro: Paz e Terra, 1982.

MOTTA, Marly Silva da. O Rio de Janeiro continua sendo ... De cidade-capital a estado da Guanabara. Tese de Doutorado. Niterói: Universidade Federal Fluminense, 1997.

NORONHA SANTOS, Francisco Agenor. Acerca da organização municipal e dos prefeitos do Distrito Federal. Rio de Janeiro: Oficinas Gráficas O Globo, 1945.

OLIVEIRA, Fabrício Augusto de. A evolução da estrutura tributária e do fisco brasileiro 18892009. Brasília: IPEA, 2010.

PINTO, Surama Conde Sá. Só para iniciados ... o jogo político na antiga capital federal. Rio de Janeiro: FAPERJ/Mauad X, 2011.

REIS, José de Oliveira. O Rio de Janeiro e seus Prefeitos. Rio de Janeiro: Prefeitura da Cidade do Rio de Janeiro, 1977. 5 vols. 
REMOND, René. Por uma história política. Rio de Janeiro: Ed. UFRJ, 1996.

SARMENTO, Carlos E. Autonomia e participação: O Partido Autonomista do Distrito Federal e o campo político carioca (1933-1937). Dissertação de Mestrado. Rio de Janeiro: UFRJ, 1996.

SILVA, Eduardo. As queixas do Povo. Rio de Janeiro: Paz e Terra, 1988.

VENEU, Marcos Guedes. Enferrujando o Sonho: Partidos e Eleições no Rio de Janeiro, 18891895. Dados: Revista de Ciências Sociais, Rio de Janeiro, vol. 30, n. 1, pp. 45-72, 1987.

WEID, Elizabeth von der et al. O Prefeito como intermediário entre o Poder Federal e o Poder Municipal na Capital da República. Rio de Janeiro: CEH/FCRB, 1984.

WIRTH, John. O fiel da balança: Minas Gerais na federação brasileira (1889-1937). Rio de Janeiro: Paz e Terra, 1975.

copyright $\odot$ @creative commons Pinto 